\title{
The Treatment Decision-making Preferences of Patients with Prostate Cancer Should Be Recorded in Research and Clinical Routine: a Pooled Analysis of Four Survey Studies with 7169 Patients
}

\author{
Andreas Ihrig $^{1}$ (D) - I. Maatouk ${ }^{1} \cdot$ H. C. Friederich ${ }^{1} \cdot$ M. Baunacke ${ }^{2} \cdot$ C. Groeben $^{2} \cdot$ R. Koch ${ }^{2} \cdot$ C. Thomas $^{2} \cdot$ J. Huber $^{2}$
}

Accepted: 2 September 2020 / Published online: 17 September 2020

(C) The Author(s) 2020

\begin{abstract}
Different patients want to take different roles in the treatment decision-making process; these roles can be classified as passive, collaborative, and active. The aim of this study was to investigate the correlation between decision-making preferences among patients with prostate cancer and personal, disease-related, and structural factors. In four survey studies, we asked 7169 prostate cancer patients about their decision-making preferences using the Control Preferences Scale (CPS) and collected clinical, psychological, and quality-of-life measures. Most patients (62.2\%) preferred collaborative decision-making, while 2322 $(32.4 \%)$ preferred an active role, and only $391(5.5 \%)$ preferred a passive role. Age $(p<0.001)$, data collection mode $(p<0.001)$, peer-to-peer support $(p=0.018)$, treatment status $(p<0.001)$, performed or planned radical prostatectomy $(p<0.001)$, metastatic disease $(p=0.001)$, and quality of life $(p<0.001)$ showed significant associations with patients' preferred decision-making roles. Oncologic risk group, anxiety, and depression were not significant in the model. In particular, younger prostate cancer patients with higher quality of life completing an online survey want to play a more active role in treatment decision-making. Before treatment has started, patients tend to prefer collaborative decision-making. Few prostate cancer patients in Germany prefer a passive role. These patients are mostly older patients, patients with a metastatic disease, and patients who have opted for prostatectomy. Whether this finding reflects a generational effect or a tendency by age group and disease phase should be investigated. Further research is also needed to describe the causalities of these relationships. The CPS offers valuable information for personal counselling and should be applied in clinical routine. In a large group of patients with prostate cancer, we found that there is a strong desire for joint decision-making with the physician before the actual treatment. Especially younger men, men with active online behaviour, and men with a high quality of life want to be actively involved in therapy decisionmaking processes.
\end{abstract}

Keywords Treatment decision-making $\cdot$ Prostate cancer $\cdot$ Health services research

\section{Introduction}

Adequate involvement of patients in treatment decisionmaking is an important goal of personalized medical care to offer each patient his or her desired role in the treatment course. Patients want to take different roles in the treatment

Andreas Ihrig

andreas.ihrig@med.uni-heidelberg.de

1 Division of Psychooncology, Department of General Internal Medicine and Psychosomatic, University Hospital of Heidelberg, INF 410, 69120 Heidelberg, Germany

2 Department of Urology, Medical Faculty Carl Gustav Carus, TU Dresden, Dresden, Germany decision-making process; these roles can be classified as passive, collaborative, and active. The Control Preferences Scale (CPS) offers a simple and fast way to assess such individual preferences [1], but it is rarely used in clinical routine. There is some evidence from research studies showing that an active role is associated with better values on patient-reported outcome measures [2-5].

Two large population-based studies deal with decisionmaking preferences [6, 7]. In a German cohort study, 3312 adults older than 64 years were recruited by their general practitioners in the course of a regular health check-up. Asked for their individual treatment decision-making preferences, $46 \%$ preferred an active role, $30 \%$ preferred a collaborative role, and $24 \%$ preferred a passive role. In a multinomial logistic regression analysis, younger age, female sex, lower 
morbidity, and higher education status were associated with preference of an active role [6].

In a US-American representative sample, 2383 adults without a history of cancer were confronted with a hypothetical cancer diagnosis and a moderate chance of survival. Asked for their treatment decision-making preferences, $8 \%$ preferred a passive role, $48 \%$ preferred a collaborative role, and $44 \%$ preferred an active role [7]. In this sample, respondents with higher education levels reported a higher preference for having a more active role in decision-making [7].

In several studies, decision preferences were also investigated in prostate cancer patients [8-16]. Preferences varied widely, but possible reasons for this observation were only investigated to a very limited extent.

The present study is intended to explore associations of the treatment decision-making preferences of prostate cancer patients with a wider range of variables. We investigated in the association between decision-making preferences and data collection mode (online vs. paper and pencil), participation in self-help groups, treatment status (before or after local treatment), radical prostatectomy (performed or planned vs. none), Gleason score, metastases, oncologic risk group, age, education, depression, anxiety, and quality of life.

\section{Methods}

In four survey studies, we asked a total of 7169 prostate cancer patients about their decision-making preferences and various psychological variables relevant to the study objective. In the first two surveys, we interviewed 686 users of an online support group (OSG) [17] and 939 participants in face-to-face support groups [18]. In a third study, 920 prostate cancer patients were investigated in a follow-up survey of the HAROW study - a large health services research study on routine care in Germany [5, 19]. All of these studies had received positive ethics statements prior to initiation. A fourth group of 4624 participants anonymously answered questionnaires regarding an online decision aid for patients with newly diagnosed non-metastatic prostate cancer [20, 21]. For the present work, we used anonymized datasets derived from these studies. Therefore, no additional ethics statement was required.

\section{Control Preferences Scale}

To determine the patients' decision-making preferences, we applied a German version of the CPS [1]. Approximately 10 years ago, our working group had the original questionnaire translated and slightly adapted for questionnaire use. Since then, we have applied it successfully in several studies [22-25]. In this adapted version of the CPS, patients are asked to read five different statements about their desired type of participation in the decision-making process (Table 1). Afterwards, they choose the statement that they perceive to be closest to their preferred role in treatment decision-making [26]. They are asked to indicate only their first preference. Two statements describe more or less autonomous roles of the patient (active). The middle statement (I prefer that my doctor and I share responsibility for deciding which treatment is best) describes equal decision-making between the physician and patient (collaborative). Two additional statements describe the physician as having a more or less dominant role in decision-making (passive). Each answer can be interpreted within the range of autonomous to paternalistic on a 5-point ordinal scale (Table 1 and Appendix).

\section{Clinical, Psychological, and Quality-of-Life Measures}

In addition to the CPS score, we assessed the Gleason score ( $\leq 6$ vs. 7 vs. $\geq 8$ ), the D'Amico oncologic risk classification (low vs. intermediate vs. high), clinical evidence for distant metastases (yes vs. no), local treatment (before or after), and radical prostatectomy (performed or planned vs. none). We also distinguished between the following groups: patients who completed the survey online vs. those who completed a paper-and-pencil version of the questionnaire, self-help users vs. patients who did not report being in such a group, and patients before treatment vs. patients who had already undergone at least one treatment. We measured depression and anxiety for capacity-related reasons with the short form of the Patient Health Questionnaire (PHQ-2) and the Generalized Anxiety Disorder Scale (GAD-2). These screening questionnaires consist of two core depression items and two core anxiety items [27]. To assess general quality of life, we used two questions from the European Organisation for Research and Treatment of Cancer Quality of Life Questionnaire Core 30 (EORTC QLQ-C30), which is an overall quality-of-life scale. The values were transformed into scores ranging from 0 to 100 , with higher scores representing better quality of life [28].

\section{Statistics}

We used analysis of variance, the Kruskal-Wallis test, and the chi-square test to compare groups. We used a common slopes cumulative logit model for ordinal responses to identify the parameters associated with the preference for a more active role in treatment decision-making. A $p<0.05$ was considered to indicate statistical significance. All calculations were performed with IBM SPSS Statistics 24 (Armonk, NY, USA) and SAS V9.4 (SAS Institute, Cary, NC, USA). 


\section{Results}

The mean age was 67.3 (SD: 7.8, median: 68, range: 39-94) years. Table 1 shows the control preferences for all patients and for the groups that completed the CPS online or with paper and pencil. Most patients $(62.2 \%)$ preferred collaborative decisionmaking. A total of 2322 (32.4\%) preferred an active role, and only $391(5.5 \%)$ preferred a passive role. Patients using the paper-and-pencil survey preferred a passive role significantly more often than online users $(9.5 \%$ vs. $4.2 \%, p<0.001)$.

For the univariate analysis, we grouped all patients according to their control preferences. The characteristics of these groups are compared in Table 2. Significant differences between the control preference groups were found in most variables. Only depressiveness and anxiety did not differ significantly between the control preference groups.

The highest percentages of patients preferring an active role were found among the youngest age group $(<51$ years: $48.4 \%$ ), self-help users (43.4\%), patients who had already undergone local treatment (38.8\%), and patients with high education levels (37.9\%).

Most patients preferring a collaborative style were patients who had low (66.5\%) or medium (65.1\%) education levels, had not yet undergone local treatment (66.5\%), had a Gleason score $\geq 8(65.5 \%)$, were not self-help users $(65.0 \%)$, were in the oldest age group $>70(64.4 \%)$, and had a moderate quality-of-life score of 51-75 (64.0\%).

The highest percentages of patients preferring a passive role were observed among patients who were older than 70 years old $(6.7 \%)$; had undergone prostatectomy $(6.1 \%)$; had already undergone local treatment (6.9\%); had low quality of life ( $\leq 50: 6.5 \%)$; and had higher oncologic risk, i.e. a Gleason score $\leq 8(6.7 \%)$, metastatic disease (7.9\%), and high oncologic risk (6.2\%).

The results of the common slopes cumulative logit model for ordinal responses are presented in Fig. 1. In this model, age $(p<0.001)$, data collection mode $(p<0.001)$, peer-to-peer support $(p=0.018)$, treatment status $(p<0.001)$, radical prostatectomy $(p<0.001)$, metastatic disease $(p=0.001)$, and quality of life $(p<0.001)$ showed significant associations with the preferred decision-making role. Oncologic risk group, anxiety, and depression were not significant in this model.

\section{Discussion}

Several previously undescribed variables related to treatment decision-making preferences in prostate cancer patients have been identified. We found significant associations between active decision-making preferences and young age, high education, online data collection mode, peer-to-peer support users, data collection before treatment, a not performed or planned radical prostatectomy, non-metastatic diseases, and high quality of life.

Regarding prostate cancer patients, the literature shows wide variation in preferences based on the CPS (Table 3). In an early investigation, the percentage of respondents with a preference for a passive role was the highest (58\%) [8]. However, a few years later, in similar populations, only 8 to $10 \%$ wanted to play a passive role $[9,10]$. In a recent investigation, $19 \%$ preferred a passive role [2]. Recently, 3348 prostate cancer survivors in Ireland were asked to describe their actual decision-making experience [11], and the percentages for each role were almost equally distributed (31\% passive, $33 \%$ shared, and $36 \%$ active). Studies by our working group also showed large differences. For example, the percentage of users of an OSG who preferred active decision-making was almost twice as high (58\%) as that of users of a face-to-face support group (33\%) [17].

The percentages of control preferences also varied widely between different countries. Compared with patients in most international studies, German prostate cancer patients very rarely $(6 \%)$ preferred a passive role [16]. More than $30 \%$ of Spanish patients with various diseases [13] preferred a passive role. Additionally, in several international investigations of prostate cancer patients, the percentages

Table 1 Results of the Control Preferences Scale

\begin{tabular}{|c|c|c|c|c|c|}
\hline & & \multirow{2}{*}{$\begin{array}{l}\text { All } \\
N=7169\end{array}$} & \multicolumn{2}{|c|}{ Data collection mode } & \multirow{2}{*}{$\begin{array}{l}\chi^{2} \\
p\end{array}$} \\
\hline & & & Online, $N=5530$ & $\begin{array}{l}\text { Paper and pencil, } \\
N=1639\end{array}$ & \\
\hline \multirow[t]{2}{*}{ Active } & I prefer to make the final treatment selection & $172(2.4 \%)$ & $113(2.0 \%)$ & $59(3.6 \%)$ & \multirow[t]{5}{*}{$<0.001$} \\
\hline & $\begin{array}{l}\text { I prefer to make the final treatment selection after } \\
\text { seriously considering my doctor's opinion }\end{array}$ & $2150(30.0 \%)$ & $1698(30.7 \%)$ & $452(27.6 \%)$ & \\
\hline Collaborative & $\begin{array}{l}\text { I prefer that my doctor and I share responsibility for } \\
\text { deciding which treatment is best }\end{array}$ & $4456(62.2 \%)$ & $3484(63.0 \%)$ & $972(59.3 \%)$ & \\
\hline \multirow[t]{2}{*}{ Passive } & $\begin{array}{l}\text { I prefer my doctor to make the final treatment decision, } \\
\text { but only after my doctor has seriously considered my opinion }\end{array}$ & $342(4.8 \%)$ & $227(4.1 \%)$ & $115(7.0 \%)$ & \\
\hline & I prefer to leave all treatment decisions to my doctor & $49(0.7 \%)$ & $8(0.1 \%)$ & $41(2.5 \%)$ & \\
\hline
\end{tabular}


Table 2 Comparison of medical data, age, quality of life, depression, and anxiety in the different control preference groups

\begin{tabular}{|c|c|c|c|c|}
\hline & Active, $N=2322$ & Collaborative, $N=4456$ & Passive, $N=391$ & $p$ \\
\hline \multicolumn{5}{|l|}{ Age } \\
\hline $\begin{array}{l}<51 \\
51-60\end{array}$ & $\begin{array}{l}77(3.3 \%) \\
467(20.1 \%)\end{array}$ & $\begin{array}{l}76(1.7 \%) \\
754(17.0 \%)\end{array}$ & $\begin{array}{l}6(1.5 \%) \\
59(15.1 \%)\end{array}$ & \multirow[t]{3}{*}{$<0.001^{\mathrm{a}}$} \\
\hline $61-70$ & $1007(43.4 \%)$ & $1902(42.8 \%)$ & $148(37.9 \%)$ & \\
\hline$>70$ & $769(33.1 \%)$ & $1716(38.6 \%)$ & $178(45.5 \%)$ & \\
\hline \multicolumn{5}{|l|}{ Education* } \\
\hline Low & $448(23.4 \%)$ & $1050(29.1 \%)$ & $76(29.6 \%)$ & \multirow{3}{*}{$<0.001^{\mathrm{C}}$} \\
\hline Medium & $510(26.7 \%)$ & $1078(29.9 \%)$ & $68(26.5 \%)$ & \\
\hline High & $754(39.4 \%)$ & $1152(31.9 \%)$ & $85(33.1 \%)$ & \\
\hline \multicolumn{5}{|l|}{ Peer-to-peer support } \\
\hline Self-help users & $716(30.8 \%)$ & $867(19.5 \%)$ & $67(17.1 \%)$ & \multirow[t]{2}{*}{$<0.001^{\mathrm{C}}$} \\
\hline None & $1606(69.2 \%)$ & $3589(80.5 \%)$ & $324(82.9 \%)$ & \\
\hline \multicolumn{5}{|l|}{ Treatment status } \\
\hline Before treatment & $1334(57.5 \%)$ & $3075(69.0 \%)$ & $215(55.0 \%)$ & \multirow[t]{2}{*}{$<0.001^{\mathrm{c}}$} \\
\hline After treatment & $988(42.5 \%)$ & $1381(31.0 \%)$ & $176(45.0 \%)$ & \\
\hline \multicolumn{5}{|l|}{ Radical prostatectomy } \\
\hline Performed/planned & $1603(69.0 \%)$ & $3245(72.8 \%)$ & $317(81.1 \%)$ & \multirow[t]{2}{*}{$<0.001^{\mathrm{c}}$} \\
\hline None & $719(31.0 \%)$ & $1211(27.2 \%)$ & $74(18.9 \%)$ & \\
\hline \multicolumn{5}{|l|}{ Gleason score } \\
\hline$\leq 6$ & $859(39.6 \%)$ & $1468(35.3 \%)$ & $111(31.1 \%)$ & \multirow{3}{*}{$<0.001^{\mathrm{k}}$} \\
\hline 7 & $1029(47.5 \%)$ & $2036(48.9 \%)$ & $179(50.1 \%)$ & \\
\hline$\geq 8$ & $279(12.9 \%)$ & $656(15.8 \%)$ & $67(18.8 \%)$ & \\
\hline \multicolumn{5}{|l|}{ Metastatic disease } \\
\hline $\mathrm{M} 0 / \mathrm{Mx}$ & $2101(32.3 \%)$ & $4059(62.4 \%)$ & $340(5.2 \%)$ & \multirow[t]{2}{*}{$0.10^{\mathrm{c}}$} \\
\hline M1 & $92(34.5 \%)$ & $154(57.7 \%)$ & $21(7.9 \%)$ & \\
\hline \multicolumn{5}{|l|}{ Risk group } \\
\hline Low & $648(29.5 \%)$ & $1094(25.9 \%)$ & $86(23.5 \%)$ & \multirow{3}{*}{$0.003^{\mathrm{k}}$} \\
\hline Intermediate & $866(39.4 \%)$ & $1734(41.1 \%)$ & $143(39.1 \%)$ & \\
\hline High & $684(31.1 \%)$ & $1392(33.0 \%)$ & $137(37.4 \%)$ & \\
\hline \multicolumn{5}{|l|}{ EORTC score } \\
\hline$\leq 50$ & $411(17.9 \%)$ & $843(19.1 \%)$ & $87(22.5 \%)$ & \\
\hline $51-75$ & $665(28.9 \%)$ & $1417(32.1 \%)$ & $132(34.2 \%)$ & \multirow[t]{2}{*}{$<0.001^{\mathrm{a}}$} \\
\hline$\geq 76$ & $1226(53.3 \%)$ & $2158(48.8 \%)$ & $167(43.3 \%)$ & \\
\hline \multirow[t]{2}{*}{ PHQ-2 } & $1.0 \pm 1.3$ & $1.0 \pm 1.2$ & $1.1 \pm 1.4$ & \multirow[t]{2}{*}{$0.14^{\mathrm{a}}$} \\
\hline & $0.5(0-6)$ & $1(0-6)$ & $1(0-6)$ & \\
\hline \multirow{2}{*}{ GAD-2 } & $1.0 \pm 1.3$ & $1.0 \pm 1.2$ & $1.1 \pm 1.4$ & \multirow{2}{*}{$0.056^{\mathrm{a}}$} \\
\hline & $1(0-6)$ & $1(0-6)$ & $1(0-6)$ & \\
\hline
\end{tabular}

*Education was not assessed in the HAROW survey

${ }^{a}$ Analysis of variance

${ }^{\mathrm{c}}$ Chi-square test

${ }^{\mathrm{k}}$ Kruskal-Wallis test

of patients with passive decision-making preferences were high: 19\% in the Netherlands [2], 31\% in Ireland [11], and $11 \%$ in Japan [15]. We found two US studies reporting low percentages of patients with passive control preferences among primarily retired servicemen from the military with prostate cancer (3-4\%) [12] and among newly diagnosed localized prostate cancer patients $(6.5 \%)$ [14]. The differences described could be due to different language versions, effects of the respective zeitgeist, or national characteristics. However, these possible influences could not be examined in the present study.

\section{Timing}

In our sample, the timing of the survey played an important role. Prostate cancer patients who were in an early stage, after 
Fig. 1 Significant variables of the common slopes cumulative logit model $(N=6703)$

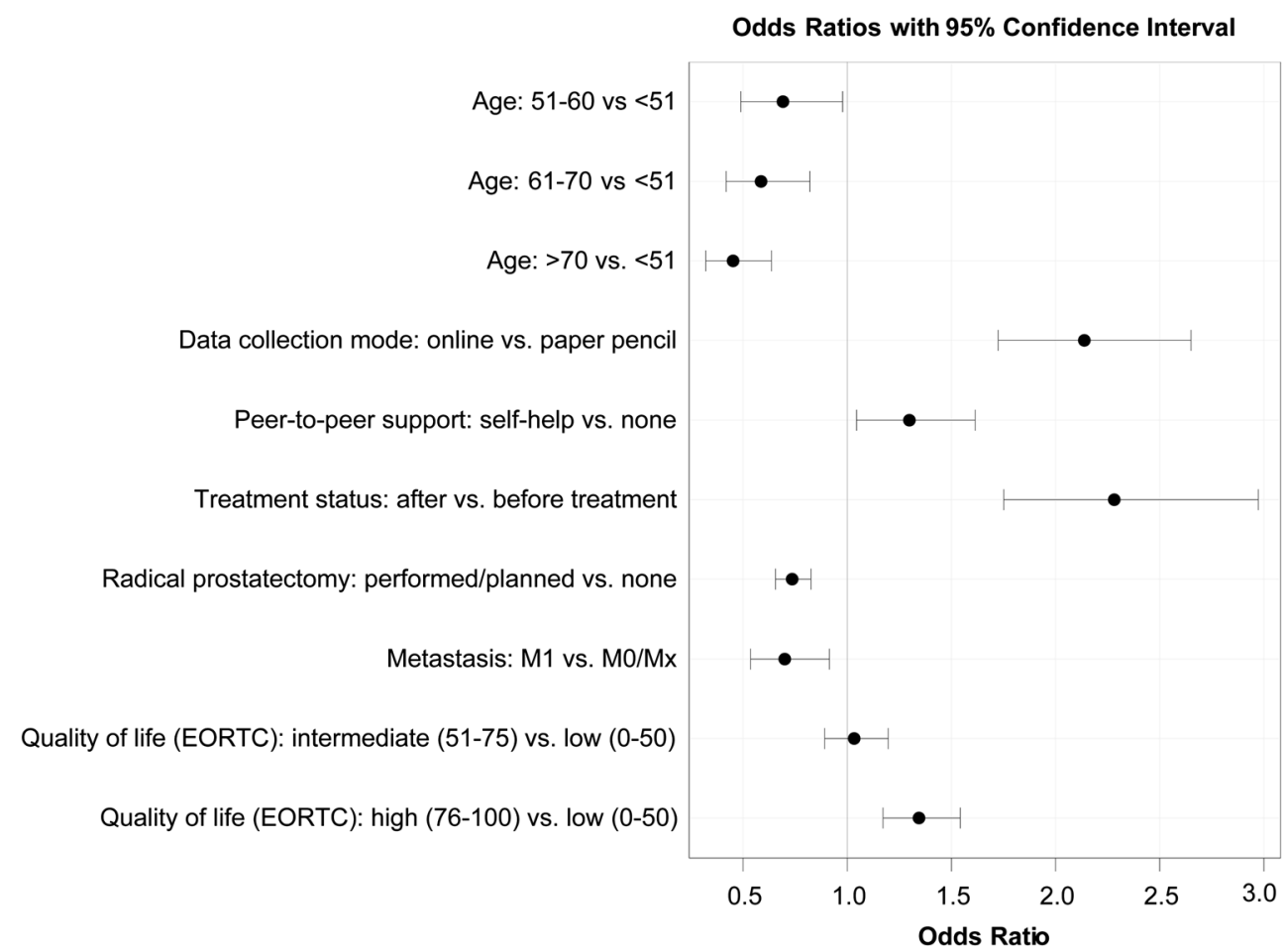

diagnosis but before treatment started, more often favoured a collaborative role. The percentage who preferred a collaborative role was lower among patients who had already started or finished their treatment. They more often preferred an active or passive role. At a later stage of treatment, when they usually gained more experience, patients seemed to develop clearer preferences. Some patients might have felt more competent and therefore wanted to have more influence on the treatment decision. After patients had already made several decisions, the perceived importance of the remaining decisions might have decreased so that patients no longer needed their physicians' help in the decision-making process. Another smaller proportion of patients tended to prefer a rather passive role after treatment. They might have either had positive experiences with physicians or simply become tired of making decisions and thus tended to leave decisions to their physicians.

\section{Age}

The correlation between decision-making preferences and age was similar to the results of other investigations. Older patients more often prefer a passive role in treatment decisionmaking [2]. The same association was found in a study with 1529 men with newly diagnosed clinically localized prostate cancer [14]. A positive association between age and the preference for a passive role has also been observed for patients with other diseases [6].

\section{Self-help}

To our knowledge, there are no results outside our working group showing a positive correlation between participation in self-help groups and an increased preference for an active role.

Table 3 Results of decision-making preferences based on the CPS in studies with prostate cancer patients

\begin{tabular}{|c|c|c|c|c|}
\hline \multirow[t]{2}{*}{ Authors and year } & \multirow[t]{2}{*}{ Population } & \multicolumn{3}{|c|}{ Preferred decision-making role } \\
\hline & & Active $(\%)$ & $\begin{array}{l}\text { Collaborative } \\
(\%)\end{array}$ & Passive $(\%)$ \\
\hline Davison, Degner et al. 1995 & 57 Canadian prostate cancer patients & 19 & 23 & 58 \\
\hline Davison, Gleave et al. 2002 & 80 Canadian prostate cancer patients & 50 & 43 & 8 \\
\hline Davison, Parker et al. 2004 & 87 Canadian transrectal biopsy patients & 43 & 47 & 10 \\
\hline Cuypers, Lamers et al. 2016 & 562 prostate cancer patients from the Netherlands & 22 & 59 & 19 \\
\hline Drummond, Gavin et al. 2018 & 3348 prostate cancer survivors in Ireland & 36 & 33 & 31 \\
\hline Ihrig, Maatouk et al. 2020 & 7169 German prostate cancer patients (pooled analysis) & 32 & 62 & 6 \\
\hline
\end{tabular}


However, the connection seems to be very understandable, as participation in self-help groups is particularly useful for prostate patients to gain information $[29,30]$ and would therefore be particularly interesting for patients who prefer an active role.

\section{Data Collection}

More patients who completed the online version of the CPS than those who completed the paper-and-pencil version wished to play an active role in the decision-making process. Since a part of our sample had the choice of whether to complete the online or paper-and-pencil version, this choice might also have been linked to general use of the Internet. This would be in line with findings from 1945 older adults who had greater odds of preferring an active role in decision-making when using the Internet [31]. On the other hand, another part of our sample did not have the choice between the two options. Therefore, this connection cannot be conclusively determined based on our data.

\section{Prostatectomy}

We found an association between the tendency of patients to opt for prostatectomy and a preference for a passive role in the decision-making process. This association could be explained by some interview statements provided by prostate cancer patients during external beam radiotherapy or their hospital stays shortly after radical prostatectomy. Patients who opted for surgery cited personal attitudes towards cancer and their desires to eradicate the cancer as quickly as possible as reasons for their treatment decisions and preferences [23]. A discussion of the treatment decision, which is a prerequisite for an informed active role, would not promote a quick solution. Other authors found that emotional distress increased the likelihood of undergoing surgery among men with localized prostate cancer [32]. However, in contrast to our results, another study of 3348 prostate cancer survivors showed that prostatectomy patients chose an active role more often than patients receiving other treatments [11].

\section{Clinical Characteristics}

We found a significant correlation between having a metastatic disease and an increased preference for a passive role. In studies with non-prostate patients, Lechner et al. also reported that multimorbid patients preferred a passive role more often than people with no or only one chronic disease. Spanish patients with various diseases showed an increased preference for a passive role with increasing disease severity [13]. This connection could be due to the fact that patients do not want to trust their own knowledge in more complex health issues, but rather the expertise of physicians.

\section{Quality of Life, Depression, and Anxiety}

Quality of life was highest among patients who preferred an active role and lowest among patients who preferred a passive role in decision-making. This association was also found in patients with myelodysplastic syndromes [33]. In a literature review of low-risk prostate cancer patients under active surveillance, 23 (55\%) of 42 empirical assessments of decision-making preferences and quality of life (including general quality-of-life, depression, and anxiety measures) showed significant correlations between the two variables [34]. No significant association between treatment decision-making and global health-related quality of life was found in 3348 prostate cancer survivors [11]. We did not find significant correlations between depression and anxiety and control preferences. Also in the literature, we did not find any studies reporting a significant relationship between decisionmaking preference and the variables depression and anxiety.

\section{Limitations}

There are several additional limitations in our study. As this is a cross-sectional study, no statements can be made about causality. The validity of the CPS, especially in different contexts, has been questioned [35]. There may be different interpretations, especially in the slight differentiation of active and passive roles. However, these subcategories are summarized in our calculations. Other instruments measuring decision-making preferences also show similar weaknesses [36]. Nevertheless, the CPS has been used in a large number of studies. In a systematic review from 2008, most studies on decision-making preferences used the CPS (Hubbard, Kidd et al. 2008). Additionally, 10 years later, a literature review on quality of life in low-risk prostate cancer patients found the CPS to be the second most common instrument used to assess this topic [34, 37]. Due to the different surveys on which our calculations are based, several problems occurred. The CPS was applied to patients in various situations, which could lead to different tendencies in the responses. In a recent study, the congruence between the roles actually experienced and the roles theoretically preferred in treatment decisionmaking was only $58 \%$ [11]. Since the parameters collected in the various surveys were somewhat different, several covariates could not be taken into account. Nevertheless, the large sample size enabled us to carry out an extensive evaluation with sufficient selection of relevant variables. Therefore, our evaluation provides a solid basis for describing relevant aspects of control preferences in prostate cancer patients.

\section{Conclusions}

In particular, younger prostate cancer patients with higher quality of life completing an online survey want to play a more active role in treatment decision-making. Before treatment has 
started, patients tend to prefer collaborative decision-making. Few prostate cancer patients in Germany prefer a passive role. These patients are mostly older patients, patients with a metastatic disease, and patients who have opted for prostatectomy. Whether this finding reflects a generational effect or a tendency in different age groups and disease phases should be investigated. Further research is also needed to describe the causalities of these relationships. Moreover, we strongly believe that the CPS offers valuable information for personal counselling and should therefore be applied in clinical routine.

Acknowledgements Open Access funding provided by Projekt DEAL. American Journal Experts provided language-editing services.

Data Availability Due to the nature of this research, participants of this study did not agree for their full data to be shared publicly, so complete data is not available. A reduced dataset of this study is available on request from the corresponding author, $\mathrm{AI}$.

\section{Compliance with Ethical Standards}

Conflict of Interest The authors declare that there is no conflict of interest.

Ethics Approval The surveys on which this study is based had been conducted with ethic approvals of the respective universities. For the present work, we used anonymized datasets derived from these studies. Therefore, no additional ethics statement was required.

Consent to Participate Informed consent was obtained from all individual participants included in the study.

\section{Code Availability Not applicable}

Abbreviations CPS, Control Preferences Scale; EORTC, European Organisation for Research and Treatment of Cancer; OR, odds ratio; HAROW, Hormone Therapy, Active Surveillance, Radiation, Operation, or Watchful Waiting

\section{Appendix}

\section{German CPS statements:}

a) Ich möchte selbst darüber entscheiden, welche medizinische Behandlung ich erhalte.

b) Ich möchte letztendlich über meine medizinische Behandlung entscheiden, nachdem ich mich ernsthaft mit der Meinung meines Arztes auseinandergesetzt habe.

c) Ich möchte, dass mein Arzt und ich die Verantwortung dafür teilen, welche Behandlung für mich am besten ist.

d) Ich möchte, dass mein Arzt die endgültige Entscheidung über meine medizinische Behandlung trifft, meine Meinung dabei aber mit einbezieht.

e) Ich möchte alle Entscheidungen, die meine medizinische Behandlung betreffen, meinem Arzt überlassen.
Open Access This article is licensed under a Creative Commons Attribution 4.0 International License, which permits use, sharing, adaptation, distribution and reproduction in any medium or format, as long as you give appropriate credit to the original author(s) and the source, provide a link to the Creative Commons licence, and indicate if changes were made. The images or other third party material in this article are included in the article's Creative Commons licence, unless indicated otherwise in a credit line to the material. If material is not included in the article's Creative Commons licence and your intended use is not permitted by statutory regulation or exceeds the permitted use, you will need to obtain permission directly from the copyright holder. To view a copy of this licence, visit http://creativecommons.org/licenses/by/4.0/.

\section{References}

1. Degner LF, Sloan JA, Venkatesh P (1997) The Control Preferences Scale. Can J Nurs Res 29(3):21-43

2. Cuypers M, Lamers RED, de Vries M, Husson O, Kil PJM, van de Poll-Franse LV (2016) Prostate cancer survivors with a passive role preference in treatment decision-making are less satisfied with information received: results from the PROFILES registry. Urol Oncol 34(11):482 e411-482 e418. https://doi.org/10.1016/j. urolonc.2016.06.015

3. van Stam MA, Pieterse AH, van der Poel HG, Bosch J, Tillier C, Horenblas S, Aaronson NK (2018) Shared decision-making in prostate cancer care: encouraging every patient to be actively involved in decision-making, or ensuring patients' preferred level of involvement? J Urol 200:582-589. https://doi.org/10.1016/j.juro. 2018.02.3091

4. Jayadevappa R, Chhatre S, Gallo JJ, Wittink M, Morales KH, Lee DI, Guzzo TJ, Vapiwala N, Wong Y-N, Newman DK (2019) Patient-centered preference assessment to improve satisfaction with care among patients with localized prostate cancer: a randomized controlled trial. J Clin Oncol 37(12):964-973

5. Baunacke M, Schmidt M-L, Groeben C, Borkowetz A, Thomas C, Koch R, Chun FK, Ihrig A, Weissbach L, Huber J (2019) Decision regret after radical prostatectomy does not depend upon surgical approach: 6-year follow-up of a large German cohort undergoing routine care. J Urol. https://doi.org/10.1097/JU.0000000000000541

6. Lechner S, Herzog W, Boehlen F, Maatouk I, Saum KU, Brenner H, Wild B (2016) Control preferences in treatment decisions among older adults - results of a large population-based study. J Psychosom Res 86:28-33. https://doi.org/10.1016/j.jpsychores. 2016.05.004

7. Spooner K, Chima C, Salemi JL, Zoorob RJ (2017) Self-reported preferences for patient and provider roles in cancer treatment decision-making in the United States. Fam Med Commun Health 5(1):43-55. https://doi.org/10.15212/FMCH.2017.0102

8. Davison BJ, Degner LF, Morgan TR (1995) Information and decision-making preferences of men with prostate cancer. Oncol Nurs Forum 22(9):1401-1408

9. Davison BJ, Gleave ME, Goldenberg SL, Degner LF, Hoffart D, Berkowitz J (2002) Assessing information and decision preferences of men with prostate cancer and their partners. Cancer Nurs 25(1): 42-49

10. Davison BJ, Parker PA, Goldenberg SL (2004) Patients' preferences for communicating a prostate cancer diagnosis and participating in medical decision-making. BJU Int 93(1):47-51

11. Drummond FJ, Gavin AT, Sharp L (2018) Incongruence in treatment decision making is associated with lower health-related quality of life among prostate cancer survivors: results from the PiCTure 
study. Support Care Cancer 26(5):1645-1654. https://doi.org/10. 1007/s00520-017-3994-Z

12. Hurwitz LM, Cullen J, Elsamanoudi S, Kim DJ, Hudak J, Colston M, Travis J, Kuo HC, Porter CR, Rosner IL (2016) A prospective cohort study of treatment decision-making for prostate cancer following participation in a multidisciplinary clinic. Urol Oncol 34(5): 233 e217-233 e225. https://doi.org/10.1016/j.urolonc.2015.11.014

13. Mira JJ, Guilabert M, Perez-Jover V, Lorenzo S (2014) Barriers for an effective communication around clinical decision making: an analysis of the gaps between doctors' and patients' point of view. Health Expect 17(6):826-839. https://doi.org/10.1111/j.13697625.2012.00809.x

14. Orom H, Biddle C, Underwood W 3rd, Nelson CJ, Homish DL (2016) What is a "good" treatment decision? Decisional control, knowledge, treatment decision making, and quality of life in men with clinically localized prostate cancer. Med Decis Mak 36(6): 714-725. https://doi.org/10.1177/0272989X16635633

15. Schaede U, Mahlich J, Nakayama M, Kobayashi H, Takahashi Y, Saito K, Uemura H, Tokumitsu M, Yoshizawa K (2018) Shared decision-making in patients with prostate cancer in Japan: patient preferences versus physician perceptions. J Glob Oncol 4:1-9. https://doi.org/10.1200/JGO.2016.008045

16. Yennurajalingam S, Rodrigues LF, Shamieh OM, Tricou C, Filbet M, Naing K, Ramaswamy A, Perez-Cruz PE, Bautista MJS, Bunge S, Muckaden MA, Fakrooden S, Sewram V, Tejedor AN, Rao SS, Williams JL, Liu DD, Park M, Lu Z, Cantu H, Hui D, Reddy SK, Bruera E (2018) Decisional control preferences among patients with advanced cancer: an international multicenter cross-sectional survey. Palliat Med 32(4):870-880. https://doi.org/10.1177/ 0269216317747442

17. Huber J, Maatz P, Muck T, Keck B, Friederich HC, Herzog W, Ihrig A (2017) The effect of an online support group on patients treatment decisions for localized prostate cancer: an online survey. Urol Oncol 35(2):37 e19-37 e28. https://doi.org/10.1016/j.urolonc. 2016.09.010

18. Huber J, Muck T, Maatz P, Keck B, Enders P, Maatouk I, Ihrig A (2018) Face-to-face vs. online peer support groups for prostate cancer: a cross-sectional comparison study. J Cancer Surviv 12(1):1-9. https://doi.org/10.1007/s11764-017-0633-0

19. Baunacke M, Schmidt M-L, Thomas C, Groeben C, Borkowetz A, Koch R, Chun FK, Weissbach L, Huber J (2019) Long-term functional outcomes after robotic vs. retropubic radical prostatectomy in routine care: a 6-year follow-up of a large German health services research study. World J Urol:1-9

20. Groeben C, Ihrig A, Holscher T, Krones T, Kessler E, Kliesch S, Wulfing C, Koch R, Wirth MP, Huber J (2016) Evaluation of the decision aid "Entscheidungshilfe Prostatakrebs" from the patients' view: results from the first three months. Urologe A 55(12):15861594. https://doi.org/10.1007/s00120-016-0265-4

21. Huber J, Valdix J, Karschuck P, Ihrig A, Hölscher T, Krones T, Kessler E, Kliesch S, Wülfing C, Thomas C (2019) The view of patients and urologists on an online decision aid for patients with non-metastatic prostate cancer: a nationwide project with over 6 , 000 users in two years. Eur Urol Suppl 18(1):e848

22. Huber J, Ihrig A, Huber CG, Hadaschik B, Pahernik S, Hohenfellner M (2011) Patient centeredness and decision-making in localised prostate cancer: possible fields of health services research in urology. Urologe A 50(6):691-696. https://doi.org/10. 1007/s00120-011-2587-6

23. Ihrig A, Keller M, Hartmann M, Debus J, Pfitzenmaier J, Hadaschik B, Hohenfellner M, Herzog W, Huber J (2011) Treatment decision-making in localized prostate cancer: why patients chose either radical prostatectomy or external beam radiation therapy. BJU Int 108(8):1274-1278. https://doi.org/10.1111/j. 1464-410X.2011.10082.x
24. Huber J, Ihrig A, Winkler E, Brechtel A, Friederich HC, Herzog W, Frank M, Grullich C, Hallscheidt P, Zeier M, Pahernik S, Hohenfellner M (2015) Interdisciplinary counseling service for renal malignancies: a patient-centered approach to raise guideline adherence. Urol Oncol 33(1):23 e21-23 e27. https://doi.org/10. 1016/j.urolonc.2014.10.017

25. Baunacke M, Groeben C, Borgmann H, Salem J, Kliesch S, Huber J (2018) Andrology on the Internet: most wanted, controversial and often primary source of information for patients. Andrologia 50(2). https://doi.org/10.1111/and.12877

26. Loeffert S, Ommen O, Kuch C, Scheibler F, Woehrmann A, Baldamus C, Pfaff H (2010) Configural frequency analysis as a method of determining patients' preferred decision-making roles in dialysis. BMC Med Inform Decis Making 10(1):47

27. Lowe B, Wahl I, Rose M, Spitzer C, Glaesmer H, Wingenfeld K, Schneider A, Brahler E (2010) A 4-item measure of depression and anxiety: validation and standardization of the Patient Health Questionnaire-4 (PHQ-4) in the general population. J Affect Disord 122(1-2):86-95. https://doi.org/10.1016/j.jad.2009.06.019

28. Aaronson NK, Ahmedzai S, Bergman B, Bullinger M, Cull A, Duez NJ, Filiberti A, Flechtner H, Fleishman SB, de Haes JC (1993) The European Organization for Research and Treatment of Cancer QLQ-C30: a quality-of-life instrument for use in international clinical trials in oncology. J Natl Cancer Inst 85(5):365-376

29. Huber J, Ihrig A, Peters T, Huber CG, Kessler A, Hadaschik B, Pahernik S, Hohenfellner M (2011) Decision-making in localized prostate cancer: lessons learned from an online support group. BJU Int 107(10):15701575. https://doi.org/10.1111/j.1464-410X.2010.09859.x

30. Seale C (2006) Gender accommodation in online cancer support groups. Health (London) 10(3):345-360. https://doi.org/10.1177/ 1363459306064495

31. Cajita MI, Whitehouse E, Budhathoki C, Hodgson N (2016) Association between Internet use and decision-making preference in older adults. Gerontechnology 14(2):97-104. https://doi.org/10. 4017/gt.2016.14.2.008.00

32. Orom H, Underwood W 3rd, Biddle C (2017) Emotional distress increases the likelihood of undergoing surgery among men with localized prostate cancer. J Urol 197(2):350-355. https://doi.org/ 10.1016/j.juro.2016.08.007

33. Efficace F, Gaidano G, Sprangers M, Cottone F, Breccia M, Voso MT, Caocci G, Stauder R, Di Tucci AA, Sanpaolo G, Selleslag D, Angelucci E, Platzbecker U, Mandelli F (2014) Preference for involvement in treatment decisions and request for prognostic information in newly diagnosed patients with higher-risk myelodysplastic syndromes. Ann Oncol 25(2):447-454. https:// doi.org/10.1093/annonc/mdt557

34. Menichetti J, Valdagni R, Bellardita L (2018) Quality of life in active surveillance and the associations with decision-making-a literature review. Transl Androl Urol 7(1):160-169. https://doi.org/ 10.21037/tau.2017.12.34

35. Henrikson NB, Davison BJ, Berry DL (2011) Measuring decisional control preferences in men newly diagnosed with prostate cancer. J Psychosoc Oncol 29(6):606-618. https://doi.org/10.1080/ 07347332.2011 .615383

36. Gartner FR, Bomhof-Roordink H, Smith IP, Scholl I, Stiggelbout AM, Pieterse AH (2018) The quality of instruments to assess the process of shared decision making: a systematic review. PLoS One 13(2):e0191747. https://doi.org/10.1371/journal.pone.0191747

37. Hubbard G, Kidd L, Donaghy E (2008) Preferences for involvement in treatment decision making of patients with cancer: a review of the literature. Eur J Oncol Nurs 12(4):299-318. https://doi.org/ 10.1016/j.ejon.2008.03.004

Publisher's Note Springer Nature remains neutral with regard to jurisdictional claims in published maps and institutional affiliations. 